\title{
Return visits to the pediatric emergency department: A multicentre retrospective cohort study
}

\author{
Colin B. Meyer-Macaulay, BScH, MD*; Mimi Truong, BSc*; Garth D. Meckler, MD, MSHS*; \\ Quynh H. Doan, MDCM, MHSc, PhD*
}

\section{ABSTRACT}

Objective: Return visits to the emergency department (RTED) for the same clinical complaint occur in $2.7 \%$ to $8.1 \%$ of children presenting to pediatric emergency departments (PEDs). Most studies examining RTEDs have focused solely on PEDs and do not capture children returning to other local emergency departments (EDs). Our objective was to measure the frequency and characterize the directional pattern of RTED to any of 18 EDs serving a large geographic area for children initially evaluated at a PED.

Methods: We conducted a retrospective cohort study of all visits to a referral centre PED between August 2012 and August 2013. We compared demographic variables between children with and without an RTED, measures of flow and disposition outcomes between the initial (index) visit and RTED, and between RTED to the original PED versus to other EDs in the community.

Results: Among all PED visits, 7.6\% had an RTED within 7 days, of which $13 \%$ were to a facility other than the original PED. Children with an RTED had higher acuity and longer length of stay on their index visit. They were also more likely to be admitted on a subsequent visit than the overall PED population. RTED to the original PED had a longer waiting time (WT), length of stay, and more frequently resulted in hospitalization than RTED to a general ED.

Conclusions: A significant proportion of RTED occur at a site other than where the original ED visit occurred. Examining RTED to and from only PEDs underestimates its burden on emergency health services.

\section{RÉSUMÉ}

Objectifs: Les reconsultations au service des urgences (RSU) pour les mêmes motifs cliniques de consultation s'observent dans une proportion de 2,7 à 8,1\% des enfants examinés aux services des urgences pédiatriques (SUP). La plupart des études portant sur les RSU se limitent aux SUP et ne tiennent pas compte des reconsultations dans d'autres services des urgences (SU) locaux. L'étude visait donc à mesurer la fréquence des RSU et à en caractériser la direction vers l'un ou l'autre des $18 \mathrm{SU}$ qui couvrent une grande région géographique, chez les enfants examinés une première fois dans un SUP.

Méthode: II s'agit d'une étude de cohorte, rétrospective, portant sur toutes les consultations faites dans un SUP d'un centre spécialisé, entre août 2012 et août 2013. II y a eu diverses comparaisons entre les enfants en ce qui concerne les variables démographiques, les consultations suivies ou non d'une RSU, les mesures de roulement des patients et les résultats cliniques au moment de la sortie du service entre les consultations initiales (de référence) et les RSU ainsi qu'entre les RSU au SUP initial et celles dans d'autres SU de la région.

Résultats: Sur toutes les consultations faites au SUP, 7,6 \% se sont soldées par une RSU dans les 7 jours suivants, dont $13 \%$ ont été demandées ailleurs que dans le SUP initial. Les enfants vus en RSU étaient dans un état plus grave et la durée de séjour a été plus longue au moment de la consultation de référence. Les probabilités d'hospitalisation chez ces enfants étaient également plus élevées au cours des consultations ultérieures que celles dans la population générale d'enfants examinés au SUP. Les RSU au SUP initial ont été associées à des délais d'attente et à des durées de séjour plus longs ainsi qu'à des hospitalisations plus fréquentes que les RSU faites dans des SU généraux.

Conclusions: Une proportion importante des RSU sont demandées ailleurs que dans le $\mathrm{SU}$ où a eu lieu la première consultation. Ainsi, le fait de limiter l'examen des RSU aux seuls SUP se traduit par une sous-estimation du fardeau pour les services de santé d'urgence.

Keywords: Return visits, patient flow, healthcare access, healthcare utilization, emergency health services

\section{INTRODUCTION}

Emergency department (ED) overcrowding is a significant problem affecting both children and adults and

From the *Department of Pediatrics, University of British Columbia, British Columbia Children's Hospital, Vancouver, BC

Correspondence to: Dr. Quynh H. Doan, Department of Pediatrics, Division of Pediatric Emergency Medicine, University of British Columbia, British Columbia Children's Hospital, 4480 Oak Street, Vancouver, BC V6H 3V4; Email: qdoan@cfri.ca 
has been linked to adverse patient outcomes. ${ }^{1,2}$ A conceptual model of ED overcrowding proposed by Asplin et al. identified three determinants of overcrowding: input factors, throughput factors, and output factors. ${ }^{3}$ Output constraints (e.g., boarding of admitted patients in the ED) are the major contributor to overcrowding of general EDs. ${ }^{3,4}$ In contrast, overcrowding in pediatric emergency departments (PEDs) has generally been attributed to input and throughput factors, with relatively less contribution of output constraints. ${ }^{3}$ Of particular importance is the idea of the reciprocal impact that return visits to the emergency department (RTED) and overcrowding may have on one another. The busiest time in the PED is in the evening, when peak patient volumes coincide with reduced access to health care providers in the community. Children initially seen during these times have a higher rate of return visits than those seen at other times. ${ }^{5}$ Concurrently, as many as two-thirds of unscheduled return visits occur during these same busy hours, further increasing patient volume. $^{6}$

An RTED is generally defined in the literature as an unscheduled ED visit for a similar or related complaint within 48 hours to 7 days of the index visit, and is a frequent occurrence. ${ }^{5-15}$ Previous studies suggest that the rate of RTED within PEDs ranges from $2.7 \%$ to $8.1 \%$ in the United States, Canada, and the UK. ${ }^{5-7,9-16}$ The variable definition of what constitutes an RTED (within 2-7 days) likely accounts for this variability in rates of RTED. Although the majority (85\%) of all ED visits by children occur in community EDs, ${ }^{1,11}$ most studies of pediatric RTED have been conducted in PEDs only, and those occurring in general EDs do not report pediatric outcomes separately. The few large studies examining multiple centres have either focused on multiple individual tertiary PEDs or do not specify the direction of RTED to and from the PED versus from the PED to a community ED. ${ }^{10-18}$

The aim of this study is to measure the incidence and describe the directional pattern of RTED for children discharged from a major tertiary care PED to any ED (pediatric and general) in a large catchment area within 7 days of the index visit and to characterize operational measures (waiting time [WT] and length of stay [LOS]) as well as outcome measures (discharge disposition) for these subsequent visits. More accurately characterizing the regional RTED rate in this way will help better estimate the burden of RTED associated with the care at a PED.

\section{METHODS}

\section{Design and study population}

We conducted a retrospective cohort study of all patients less than 17 years of age who presented initially to British Columbia Children's Hospital (BCCH) over a 1-year period from August 1, 2012, to August 8, 2013, using the PED administrative database. The 53rd week period was included to account for only any RTED that may have been triggered by the 52nd week included in our study period. BCCH is a tertiary children's hospital in metropolitan Vancouver, is the only pediatric referral centre in British Columbia, and receives just over 40,000 visits per year, serving children up until their 17 th birthday. We also reviewed data for pediatric visits from all 17 community/general EDs that see both children and adults in Vancouver Lower Mainland. Together, the 18 EDs included in the study provide care for a population of over 2.5 million people, or nearly $60 \%$ of the province. In addition to these 18 EDs, children in this area may also access medical care through walk-in urgent care clinics and family physicians, through the British Columbia universal health care coverage.

\section{Linkage and database preparation}

A data custodian merged pediatric visits from all study sites, taking care to identify the visit sites. Once merged, study subjects' personal health numbers were replaced with a unique study number, allowing us to link multiple ED visits to any of the study sites by the same subject. We included only visits for which the chronologically earlier visit occurred at the study PED. We took this visit to be the incident or "index" visit. To be considered an RTED, linked ED visits had to fulfill the following criteria: 1) The time-lapse between visits was $\leq 7$ days, and 2) the subsequent visit was for the same clinical condition as the index visit. To determine whether initial and RTED clinical conditions were related, we examined both their National Ambulatory Care Reporting System (NACRS) ${ }^{19}$ codes for chief complaint and discharge diagnosis. NACRS codes are the standard reporting codes for ED visits in Canada. Discharge diagnosis and chief complaint codes are presented with a letter and a number, where the letter represents a category of diseases and the number corresponds with a specific 
diagnosis or complaint. If the paired visits shared the same disease category, the visits were considered to be related, otherwise, the visits were further evaluated by two reviewers, where the final decision was made by the senior reviewer. Where discharge diagnosis was not available due to a disposition of left without being seen (LWBS), the chief complaint was used to determine whether the visits were related. In cases where there was more than one RTED, we applied the same criteria to determine whether additional visits were related. The data available did not enable us to differentiate between planned and unplanned RTED.

We extracted the following demographic and visit characteristics from the administrative databases for each visit: age, sex, visit site, triage acuity level using the Canadian Triage and Acuity Scale (CTAS), reason for visit, date and time of initial contact (triage or registration, whichever occurred chronologically earlier), date and time initially seen by the physician, date and time of disposition, discharge diagnosis, discharge disposition (transferred, admitted, discharged, death, LWBS, or left against medical advice [LAMA]). The institutional ethics boards for participating sites reviewed and approved this study. Given the low risk to patient confidentiality of this retrospective administrative database design, a waiver of consent was approved.

\section{Study objectives and outcome measures}

Our primary objective was to determine the proportion of children initially presenting to a tertiary PED with an RTED (PED or general ED) both within 72 hours and within 7 days of the incident visit to compare the rate of return visits using both the upper and lower limits for RTEDs reported in the current literature. Our secondary objective was to describe and compare measures of ED flow (WT and LOS) and disposition between a) the index visit and the first RTED against all visits to the PED, to highlight the difference in utilization characteristics of children who come back to the ED and those who do not; b) the index visit compared to the first RTED; and c) RTED occurring at the PED against RTED at a general ED. The outcome measures included ED LOS, WT to physician assessment, proportion of visits being admitted to an inpatient ward, and proportion of LWBS.

\section{Analyses}

We used descriptive statistics to report all outcomes. We presented continuous variables (LOS, WT) using medians and interquartile range (IQR). We used proportions to present bivariate variables (rates of return visits, rate of admissions). We used the MannWhitney $U$ test to evaluate the difference between unpaired continuous outcome measures (LOS and WT between index and overall PED visits) and the Wilcoxon signed ranks test to evaluate the difference between paired outcome measures (LOS and WT between index and their RTED). We used the chisquare test to compare binary outcomes such as 1) rate of admission between index visits and RTED, 2) CTAS distribution between children with and without return visits to the PED, 3) CTAS distribution between index and repeat visits to the ED, and 4) CTAS distribution on the index visit between children who were admitted and those who were discharged on the RTED.

\section{RESULTS}

\section{Rates of return visits}

During the study period, the PED received 43,596 visits, of which $3,311(7.6 \%)$ had an RTED within 7 days, including 2,540 (5.8\%) for which the RTED was within 72 hours. Our review also identified 88 index visits with return presentations deemed unrelated to the original visit diagnosis and were excluded from further analyses. Of all RTED within 7 days, 2,866 (87\%) returned to the $\mathrm{PED}$, and 426 (13\%) returned to another facility. Among children with repeat visits to the ED, $80.0 \%$ had one repeat visit only; for those with more than one RTED, the average number of return visits was 2.4 (standard deviation 0.7, range 1-6).

\section{Characteristics of subjects with and without return visits}

Table 1 describes the demographic details of the study population. Compared to all other PED visits, the group of children who had a subsequent RTED had a higher triage acuity at their index visit (CTAS-1 0.2\%, CTAS -2 15.6\%, CTAS-3 42\%, CTAS- 4 40.5\%, CTAS-5 $1.6 \%$ v. CTAS-1 $0.5 \%$, CTAS-2 $13.7 \%$, CTAS-3 $37.1 \%$, CTAS-4 45.5\%, CTAS-5 $3.2 \%$, $p<0.01)$. Measures of flow and disposition for visits at the PED are shown in Table 2. The LWBS proportion 


\begin{tabular}{|c|c|c|c|}
\hline Variable & All visits to PED & Index visit & 1 st return visit \\
\hline Total & 43,596 & 3,311 & 3,311 \\
\hline Mean age in years $(95 \% \mathrm{Cl})$ & $5.5(5.4,5.5)$ & $5(4.8,5.1)$ & $5(4.8,5.1)$ \\
\hline Sex (proportion male) & $56.2 \%$ & $56.8 \%$ & $56.3 \%$ \\
\hline \multicolumn{4}{|c|}{ Acuity distribution by CTAS ( $n, \%)$} \\
\hline 1 & $213(0.5 \%)$ & $7(0.2 \%)$ & $9(0.3 \%)$ \\
\hline 2 & $5,960(13.7 \%)$ & $512(15.6 \%)$ & 360 (10.9\%) \\
\hline 3 & $16,127(37.1 \%)$ & $1,379(42.0 \%)$ & $1,411(42.9 \%)$ \\
\hline 4 & $19,787(45.5 \%)$ & $1,330(40.5 \%)$ & $1,375(41.8 \%)$ \\
\hline 5 & 1,399 (3.2\%) & $53(1.6 \%)$ & $137(4.2 \%)$ \\
\hline
\end{tabular}

Table 2. Measures of ED flow and disposition comparing all PED visits and the index and first RTED

\begin{tabular}{|c|c|c|c|}
\hline Outcome & All visits to PED & Index visit & First RTED \\
\hline Median ED LOS in minutes (IOR) & $185(117,283)$ & $210^{*}(131,215)$ & $179^{\dagger}(111,291)$ \\
\hline Median ED WT in minutes (IQR) & $90(50,149)$ & $91(50,148)$ & $81^{\dagger}(44,139)$ \\
\hline Discharged $(n, \%)$ & $38,185(87.6 \%)$ & $2,993(90.5 \%)$ & $2,853(87.0 \%)$ \\
\hline Admitted (n, \%) & $3,613(8.3 \%)$ & $95(2.9 \%)$ & $320(9.8 \%)$ \\
\hline Transferred (n, \%) & $30(0.1 \%)$ & $2(0.1 \%)$ & $3(0.1 \%)$ \\
\hline Died $(n, \%)$ & $0(0 \%)$ & $0(0 \%)$ & $0(0 \%)$ \\
\hline LWBS (n, \%) & $1,677(3.9 \%)$ & $216\left(6.5 \%{ }^{\ddagger}\right)$ & $98(3.0 \%)$ \\
\hline LAMA (n, \%) & $74(0.2 \%)$ & $3(0.1 \%)$ & $5(0.2 \%)$ \\
\hline \multicolumn{4}{|c|}{$\begin{array}{l}\text { ED = emergency department; LAMA = left against medical advice; LOS = length of stay; LWBS = left without being seen; PED = pediatric emergency } \\
\text { department; RTED = return to emergency department; } W T=\text { waiting time. } \\
{ }^{*} p<0.001 \text { (index visit } v \text {. all PED visits). } \\
{ }^{+} p<0.001 \text { (first RTED compared to index visit). } \\
{ }^{+} p<0.01 \text { (index visit } v \text {. all PED visits). } \\
\text { Note that the admission rate of } 2.9 \% \text { on the first visit to the emergency department indicates that } 2.9 \% \text { of patients with a return visit to the emergency } \\
\text { department for the same clinical complaint were admitted, subsequently discharged, and returned to the ED within } 7 \text { days of their initial visit. }\end{array}$} \\
\hline
\end{tabular}

was higher among index visits of children with a subsequent RTED than among the overall PED visit population $(6.5 \%$ compared to $3.9 \%, p<0.001)$. ED LOS was longer for patients with a subsequent RTED than the overall PED population (210 minutes $v$. 185 minutes $p<0.001)$. On the index visit, infectious diseases accounted for $>40 \%$ of diagnoses resulting in an RTED. The five most common diagnoses at the index visit associated with an RTED are listed in Table 3.

\section{Characteristics of return visits}

At the RTED, the distribution of triage acuity was lower on the return visit compared to the index visit (CTAS-1 $0.3 \%$, CTAS-2 10.9\%, CTAS-3 42.9\%, CTAS-4 41.8\%, CTAS-5 4.2\% v. CTAS- 1 $0.2 \%$, CTAS-2 15.6\%, CTAS-3 42.0\%, CTAS-4 $40.5 \%$, CTAS $-51.63 \%, p<0.01)$. The rate of hospital
Table 3. Top five most common discharge diagnoses of children with an associated RTED

\begin{tabular}{ll} 
Discharge diagnosis & N (\%) \\
\hline Viral infection & $491(14.8 \%)$ \\
Upper respiratory tract infection & $239(7.2 \%)$ \\
Fever & $223(6.7 \%)$ \\
Gastroenteritis & $204(6.2 \%)$ \\
Tissue infection & $187(5.6 \%)$
\end{tabular}

admission was slightly higher on the first RTED than that found in the overall PED population $(9.8 \% \mathrm{v}$. $8.3 \%, p<0.01)$. Of note, among children with one or more RTED, 95/3,311 (2.9\%) were admitted on their index visit, discharged from the in-patient ward, and subsequently returned to the ED for the same complaint within 7 days of their index PED visit, despite their initial hospital admission.

Although the proportion of LWBS was higher among subjects with an RTED than the overall PED 


\begin{tabular}{|c|c|c|}
\hline Characteristics & PED & General ED \\
\hline Total $(n, \%)$ & $2,871(87.0 \%)$ & $440(13.0 \%)$ \\
\hline Age in years mean (SD) & $5.0(4.9)$ & $5.7(4.8)$ \\
\hline Male \% & $55.7 \%$ & $58.2 \%$ \\
\hline \multicolumn{3}{|l|}{ CTAS (n, \%) } \\
\hline 1 & $6(0.2 \%)$ & $3(0.7 \%)$ \\
\hline 2 & $318(11.1 \%)$ & $42(9.9 \%)$ \\
\hline 3 & $1,203(42.0 \%)$ & $208(48.8 \%)$ \\
\hline 4 & $1,219(42.5 \%)$ & $156(36.6 \%)$ \\
\hline 5 & $120(4.2 \%)$ & $17(4.0 \%)$ \\
\hline \multicolumn{3}{|l|}{ Measures of flow } \\
\hline Median ED LOS in min (IQR) & $186(116,302)$ & $132(76,214)^{*}$ \\
\hline Median ED WT in min (IQR) & $88(50,146)$ & $44(20,87)^{*}$ \\
\hline \multicolumn{3}{|l|}{ Disposition (n, \%) } \\
\hline Discharged & $2,483(86.5 \%)$ & $370(90.1 \%)$ \\
\hline Admitted & $305(10.6 \%)$ & $15\left(3.7 \%^{\dagger}\right)$ \\
\hline Transferred & $3(0.1 \%)$ & $0(0 \%)$ \\
\hline Died & $0(0 \%)$ & $0(0 \%)$ \\
\hline LWBS & $75(2.6 \%)$ & $23(5.6 \%)$ \\
\hline LAMA & $5(0.2 \%)$ & $0(0 \%)$ \\
\hline \multicolumn{3}{|c|}{$\begin{array}{l}{ }^{*} p<0.001 . \\
+p<0.01 . \\
C T A S=\text { Canadian Triage and Acuity Scale; } E D=\text { emergency department; } L A M A=\text { left } \\
\text { against medical advice; } L O S=\text { length of stay; LWBS = left without being seen; } \\
\text { PED = pediatric emergency department; } R T E D=\text { return to emergency department; } \\
\text { SD = standard deviation; } W T \text { = waiting time. }\end{array}$} \\
\hline
\end{tabular}

population during their index visit, the proportion of LWBS during RTED was similar to the overall PED population at $3.0 \%$. Median ED LOS was longer on the index visit than on the first RTED (210 minutes v. 179 minutes, $p<0.001)$.

\section{Return visits to the PED versus general ED}

Children returning to the PED had a much higher rate of admission than those returning to a general ED $(10.6 \%$ v. $3.7 \%, p<0.01)$. Both median ED LOS and WT were longer on the first RTED when it occurred in the PED compared to a general ED (186 minutes v. 132 minutes, $p<0.001$ and 88 minutes v. 44 minutes, $p<0.001$, respectively). A comparison of demographic information and outcomes between RTED at the PED versus a general ED is shown in Table 4.

\section{Missing data}

With the exception of WT, where the data were missing for about $20 \%$ of all subjects, the proportion of subjects with missing values on all other variables was trivial. Triage CTAS category was missing for 110/ 43,596 in the overall PED population, 30/3,311 patients on the index visit with an RTED, and 19/3,311 patients on their first RTED (possibly because they left prior to triage and CTAS assignment). LOS data were missing for $6 / 43,596$ in the overall PED population, $1 / 3,311$ patients at the index visit, and 1/3,311 patients on their first RTED. Information on disposition was missing for $17 / 43,596$ patients in the overall PED population, $2 / 3,311$ patients at the index visit, and 32/3,311 patients on their first RTED.

\section{DISCUSSION}

This study of RTED from a PED includes those children who returned to any of the 17 community/general EDs in addition to the tertiary PED at which the index visit occurred, thereby providing a more complete measure of RTED within a large metropolitan catchment area. As expected, the proportion of children with a return visit, when including return visits to community EDs (7.6\%), is on the high end of the range reported in the current literature $(2.7 \%$ to $8.1 \%) .{ }^{5-7,9-14,16}$ RTED to only the original PED significantly underestimates the burden of return visits in this study by approximately $15 \%(6.6 \%$ v. $7.6 \%)$.

Only a few previous large studies have examined pediatric RTED to multiple sites. ${ }^{11-18}$ Three of these multicentre studies included patients of all ages, including adults. ${ }^{15-17}$ Two large studies reported low rates of RTED: Akenroye et al. described a 3.3\% RTED to and from PEDs but did not capture returns to general EDs and focused their study on identifying factors associated with admission upon RTED. ${ }^{12}$ Cho et al. reported a $2.7 \%$ RTED rate using a large administrative database from the National Ambulatory Care Hospital Survey, but only visits to and from the same ED were examined, and the ED type was not reported. ${ }^{11}$ At the high end of the range, Saunders et al. reported a pediatric RTED rate of $7.5 \%$ among a multicentre cohort in Ontario, ${ }^{13}$ and Montalbano et al. reported the highest published pediatric RTED rate of $8.1 \%$ among a sample of children with Medicaid in the United States. ${ }^{14}$ The Saunders study focused specifically on the impact of family immigration status on return visits or adverse outcomes and did not report RTED according to site or type of ED. Although the Montalbano study described pediatric patients who returned for care to urgent care or office clinic settings 
following an ED visit, these comprised a small proportion of return visits, and the type of ED and directionality of RTED were not reported among their RTED cohort. Therefore, our study contributes to a further understanding of how children treated in a PED who return for care related to their index visit impact not only the PED but also other community EDs as well, and may offer a more accurate estimation of the true incidence of RTED resulting from visits to a PED, particularly within the context of the Canadian universal health care system where patients are not restricted to specific networks of care within the context of individual insurance plans.

Previous research on return visits has used variable definitions, with a time frame from 48 hours to 7 days following the index visit. We found that including revisits up to 7 days after the index visit captured an additional $30 \%(5.8 \%$ v. $7.6 \%)$ of children who sought care for the same complaint compared to a window of 72 hours, suggesting that shorter definitions of RTED may underestimate the true burden. Moreover, published reports with lower proportions of RTED often exclude index visits with a disposition of LWBS, LAMA, or admission to the hospital. ${ }^{10} \mathrm{We}$ found that these index visits represent a significant number of patients who ultimately return to an ED for evaluation of the same complaint, thereby adding to ED input factors that contribute to further ED crowding and should therefore be included to provide a more accurate assessment of the overall burden of RTED on ED resources.

Controversy exists over whether RTED are an indicator of ED safety/quality or reflect a larger systems failure that might be preventable. ${ }^{2,16}$ Previous studies have shown that parents of children who had an RTED were generally satisfied with the care they received on their initial visit ( $94 \%$ satisfaction rate), but a significant majority cited lack of access to a family physician as a primary reason for their return visit. ${ }^{9}$ On the other hand, a study by Easter and Bachur (2012) found that among children who returned to the ED and required admission to the hospital, $13 \%$ had received medical care/counselling that was deemed deficient by an independent reviewer, suggesting that the RTED may be a marker of poor quality of care. ${ }^{8}$

Numerous studies have found specific demographic variables associated with an RTED (i.e., chronic disease, higher acuity on presentation, younger age, underlying diagnosis, time of arrival to the PED, lack of access to primary care and a disposition of LWBS on the index visit). ${ }^{5-13}$ With the exception of LWBS, these risk factors are not modifiable in the ED. In addition, studies examining the impact of RTED have generally used disposition outcomes (i.e., proportion admitted) to evaluate the impact of RTED on resource utilization, while we chose to also focus on measures of emergency ED flow (WT and LOS). Our study found that children with an RTED had several markers of increased disease severity or health care utilization on their index visit (increased acuity, longer LOS, and higher rates of admission on RTED), suggesting that follow-up, unscheduled or scheduled, may have been appropriate, in some cases. However, triage acuity overall decreased between the index and RTED, suggesting that it is possible or even likely that a non-ED follow-up setting may have been appropriate for some.

We also noted a higher admission rate if the RTED occurred at the PED than at a general ED $(10.6 \% \mathrm{v}$. $3.7 \%, p<0.01)$. This is despite the observation that the triage acuity level of RTED was generally lower at the PED than at general EDs (see Table 4). Whether this reflects systematic variability in triage acuity assignment between a PED and ED triaging, or self-selection by families with regard to which ED to return to, is unclear. Large multicentre observational studies have validated the use of the pediatric CTAS for children in the PED, demonstrating both high inter-rater reliability and its robust ability to predict health services utilization, but these studies have not yet included the pediatric population receiving care in a non-PED institution. $^{20-23}$ Although we have not found any study exploring families' preferences for ED sites when returning for further emergency care, one study did document significant differences in both patient characteristics (younger) and clinical outcomes (more frequently hospitalized) in children assessed at PEDs compared to general EDs that would support the notion that children brought back to a PED rather than to a general ED may follow a similar pattern. ${ }^{24}$ In Canada, it is common for a single tertiary care referral centre to service a large geographic area; therefore, preference for a return visit site may simply reflect proximity. Future studies are planned to characterize the bi-directional nature of pediatric RTED, including those with an index visit in the community to better understand the complex pattern of ED utilization among children.

Limitations of our study include those inherent to all retrospective administrative databases. Information 
related to the hospital course for children admitted at the index visit was not available, therefore limiting our ability to comment on reasons for return visits following hospitalization, which are expectedly very different from those who were discharged; also, we were unable to distinguish between an RTED that was scheduled (i.e., told to return for re-evaluation) and unscheduled. Recognizing that root cause analyses of potentially modifiable factors associated with RTED (whether discharged or hospitalized at the index visit) are important but would require a different approach (detailed medical chart review) and would not be feasible with the size of this study's population and the number of sites where charts would have to be pulled from, we have initiated a separate study with a reduced study population scope.

Similarly, completeness of data available was inconsistent, in that, although data on LOS were available for nearly all children presenting to the PED, just under $80 \%$ had documented WTs, making this estimation less reliable. Moreover, it is possible that families who first sought care for their child at the BCCH PED had an RTED beyond the 18 included centres in our study. This would imply that they either reside within the studied catchment area but opted to drive out of their way to seek further emergency care or reside outside of the catchment area and, upon repeat ED visits, chose to seek care locally. Although we cannot capture the magnitude of the frequency of the first scenario proposed, our previously published study on the trend of PED utilization found that only less than $3.5 \%$ of our PED users reside outside of the BCCH and Lower Vancouver Mainland area, which are covered by our study EDs. ${ }^{25}$

An additional limitation of this cohort study is that the discharge diagnosis NACRS codes were assigned by individual clinicians (nurses and physicians) or unit clerks using diagnostic terms written by the clinicians depending on the site. We did not review individual ED charts, thereby relying on the diagnostic categorization of individual practitioners.

Finally, data summaries and the interpretation we offer here relate to an environment where there is only one referral PED centre in a large geographic area and where most emergency care to children is provided in a general or community hospital with mixed adultpediatric EDs, and thus may not be generalizable to other health care models.

Strengths of this study include our large data set and geographic area covered, likely capturing all RTED resulting from visits originating at our PED, regardless of the choice of site at the RTED. Future research might further explore the directional pattern and magnitude of the burden of pediatric RTED, where the index visit occurred in a general ED in the community.

\section{CONCLUSION}

This study found that the incidence of RTED associated with visits to a PED is higher than most previous estimates, when return visits to any of the community EDs within a large catchment area are considered, with an additional $15 \%$ of RTED occurring at EDs other than at the index PED. Furthermore, we found important differences in resource utilization related to a return visit (i.e., WT, LOS, admission rate) between those that occurred in a PED and those in a general ED.

Acknowledgements: The Michael Smith Foundation for Health Research Scholars supported this research.

Competing interests: None declared.

\section{REFERENCES}

1. Hostetler MA, Mace S, Brown K, et al. Emergency department overcrowding and children. Pediatr Emerg Care 2007;23(7):507-15, doi:10.1097/01.pec.0000280518.36 408.74.

2. Timm N, Ho M, Luria J. Pediatric emergency department overcrowding and impact on patient flow outcomes. Acad Emerg Med 2008;15(9):832-6, doi:10.1111/j.1553-2712. 2008.00224.x.

3. Asplin B, Magid D, Rhodes K, et al. A conceptual model of emergency department crowding. Ann Emerg Med 2003; 42(2):173-80, doi:10.1067/mem.2003.302.

4. Stang AS, McGillivray D, Bhatt M, et al. Markers of overcrowding in a pediatric emergency department. Acad Emerg Med 2010;17(2):151-6, doi:10.1111/j.1553-2712. 2009.00631.x.

5. Goldman R, Ong M, Macperson A. Unscheduled return visits to the pediatric emergency. Pediatr Emerg Care 2006;22(8):545-9, doi:10.1097/01.pec.0000230553. 01917.05 .

6. Alessandrini EA, Lavelle JM, Grenfell SM, et al. Return visits to a pediatric emergency department. Pediatr Emerg Care 2004;20(3):166-71.

7. Goldman RD, Kapoor A, Mehta S. Children admitted to the hospital after returning to the emergency department within 72 hours. Pediatr Emerg Care 2011;27(9):808-11, doi:10.1097/PEC.0b013e31822c1273.

8. Easter JS, Bachur R. Physicians' assessment of pediatric returns to the emergency department. 7 Emerg Med 2013; 44(3):682-8, doi:10.1016/j.jemermed.2012.05.011. 
9. Ali AB, Place R, Howell J, et al. Early pediatric emergency department return visits: a prospective patient-centric assessment. Clin Pediatr (Phila) 2012;51(7):651-8, doi:10.1177/ 0009922812440840.

10. O'Loughlin K, Hacking KA, Simmons N, et al. Paediatric unplanned reattendance rate: $\mathrm{A} \& \mathrm{E}$ clinical quality indicators. Arch Dis Child 2013;98(3):211-3, doi:10.1136/ archdischild-2012-302836.

11. Cho CS, Shapiro DJ, Cabana MD, et al. A national depiction of children with return visits to the emergency department within 72 hours, 2001-2007. Pediatr Emerg Care 2012;28(7):606-10, doi:10.1097/PEC.0b013e $31825 \mathrm{cf} 7 \mathrm{cf}$.

12. Akenroye A, Thurm CW, Neuman MI, et al. Prevalence and predictors of return visits to pediatric emergency departments. 7 Hosp Med 2014;9(12):779-87, doi:10.1002/ ihm.2273.

13. Saunders N, To T, Parkin P, et al. Emergency department revisits by urban immigrant children in Canada: a population-based cohort study. JPEDS 2016;170: 218-26.

14. Montalbano A, Rodean J, Kangas J, et al. Urgent care and emergency department visits in the pediatric Medicaid population. Pediatrics 2016;137(4):e20153100, doi:10.1542/ peds.2015-3100.

15. Calder L, Pozgay A, Riff S, et al. Adverse events in patients with return emergency department visits. BM7 Qual Saf 2015;24(2):142-8, doi:10.1136/bmjqs-2014-003194.

16. Pham JC, Kirsch TD, Hill PM, et al. Seventy-two-hour returns may not be a good indicator of safety in the emergency department: a national study. Acad Emerg Med 2011;18(4):390-7, doi:10.1111/j.1553-2712.2011.01042.x.
17. Ko M, Lee Y, Chen C, et al. Incidence of and predictors for early return visits to the emergency department: a population-based survey. Medicine (Baltimore) 2015;94(43): 1-8, doi:10.1097/MD.0000000000001770.

18. Sung SF, Liu KE, Chen SC, et al. Predicting factors and risk stratification for return visits to the emergency department within 72 hours in pediatric patients. Pediatr Emerg Care 2015;31(12):819-24, doi:10.1097/PEC.0000000000000417.

19. Unger B, Afilalo M, Boivin JF, et al. The Canadian emergency department diagnosis shortlist; 2015. Available at: https:// www.cihi.ca/en/types-of-care/hospital-care/emergency-andambulatory-care/nacrs-metadata (accessed 29 November 2016).

20. Gravel J, Gouin S, Goldman RD, et al. The Canadian Triage and Acuity Scale for children: a prospective multicenter evaluation. Ann Emerg Med 2012;60(1):71-7, doi:10.1016/j.annemergmed.2011.12.004.

21. Gravel J, Fitzpatrick E, Gouin S, et al. Performance of the Canadian Triage and Acuity Scale for children: a multicenter database study. Ann Emerg Med 2013;61(1):27-32.

22. Gravel J, Manzano S, Arsenault M. Validity of the Canadian Paediatric Triage and Acuity Scale in a tertiary care hospital. CFEM 2009;11(1):23-8.

23. Gravel J, Gouin S, Manzano S, et al. Interrater agreement between nurses for the Pediatric Canadian Triage and Acuity Scale in a tertiary care center. Acad Emerg Med 2008;15(12):1262-7, doi:10.1016/j.ajem.2008.02.024.

24. Nelson D, Walsh K, Fleisher G. Spectrum and frequency of pediatric illness presenting to a general community hospital emergency department. Pediatrics 1992;90:5.

25. Doan Q, Genuis E, Yu A. Trends in utilization and flow outcomes in a Canadian pediatric emergency department. C7EM 2014;16(5):405-10. 